\title{
Knowledge Attitude and Practice of Biomedical Waste Management among Health Care Workers in a Tertiary Care Hospital, Coimbatore, India
}

\author{
K. Deepika* \\ Department of Microbiology, Karpagam Faculty of Medical Sciences and Research, \\ Coimbatore, India \\ *Corresponding author
}

Ke y w o r d s
Knowledge,
Attitude, Practice,
health care workers,
Biomedical waste
management

A B S T R A C T

Advances in scientific development and research activities and patient care activities the amount of waste generated is increasing in amount day by day. About 10 to $25 \%$ of the hospital waste is considered hazardous and possess serious health threats. Lack of knowledge about proper segregation and disposal of the health care waste may cause various threats and hazards. All health care workers including doctors, nursing staffs, laboratory technicians, housekeeping individuals are working in our hospital. Observational Cross sectional study conducted in our hospital in November and December months of 2018. A total of 213 health care professionals were included in the study including 135 CRRI s, 63 Staff nurses, 10 lab technicians, and 5 class IV workers. Majority of the CRRIs (87.5\%) and Lab technicians $(90.9 \%)$ had good knowledge regarding the waste segregation and legislation of BMW management rules while only $25 \%$ of the class IV workers had good knowledge regarding the same. From our present study it can be concluded that the knowledge and awareness is less among the health care workers and inadequate and poor among the class IV workers. Frequent training sessions followed by the surveillance of their activities by a team would help to reinforce the importance of proper biomedical waste management

\section{Introduction}

Hospital is a complex space which has normal inhabitants of the hospital (i.e., nursing staffs, patient and doctors) and is also visited frequently by people from every walk of life in the society. Due to advances in scientific development and research activities and patient care activities the amount of waste generated is increasing in amount day by day.
As mentioned in of the Government of India's Biomedical Waste (Management and Handling) Rules 1998 schedule I. The term "biomedical waste" has been defined as "any waste that is generated during diagnosis, treatment or immunisation of human beings or animals, or in the research activities pertaining to or in the production or testing of biological" [2]. The amount of hospital waste generated in India annually is an approximate 
of 0.33 million tons and the average rate is 0.5 $\mathrm{kg}$ to $2 \mathrm{~kg}$ per bed per day [3]. About 10 to $25 \%$ of the hospital waste is considered hazardous and possess serious health threats [4]. Lack of knowledge about proper segregation and disposal of the health care waste may cause various threats and hazards to mankind like the transmission of diseases to a wide group of patients, their attenders and other health workers.

The risk of transmission of diseases like HIV, Hepatitis B and HCV are increased with improper waste disposal and also possess threat for air, water and soil pollution leading harm to the environment [5]. Knowledge on proper biomedical waste management including waste handling, segregation and disposal is needed for the prevention and spread of dreaded diseases.

Therefore this study was undertaken to assess the knowledge, attitude and practice of BMW management among the different group of health care workers in a tertiary care hospital in Coimbatore.

\section{Materials and Methods}

\section{Study population}

The health care workers should be trained adequately and be able to propagate the information to others and apply the same in practice. Pitfalls in the above situations have made health care facilities a hub for the transmission of infectious diseases. All health care workers including doctors, nursing staffs, laboratory technicians, housekeeping individuals working in our hospital

\section{Type of study}

Observational cross sectional study conducted in our hospital in November and December months of 2018

\section{Methods}

After obtaining Institute ethics committee approval and informed written consent from the participants, the study was pretested in a small group of 5 members from each participant group and was asked to report if they were unable to understand any questions. Thena pretested and structured questionnaire was given to the health care workers including CRRI s, Nursing staffs, laboratory technicians and Class IV workers for data collection. Confidentiality of the participants was strictly guaranteed and maintained. The data obtained were analysed using SPSS software.

\section{Inclusion criteria}

People who consented to participate in the study

\section{Exclusion criteria}

People who did not consent to participate in the study.

\section{Results and Discussion}

A total of 213 health care professionals were included in the study including 135 CRRI s, 63 Staff nurses, 10 lab technicians, and 5 class IV workers. Majority of the CRRIs $(87.5 \%)$ and Lab technicians $(90.9 \%)$ had good knowledge regarding the waste segregation and legislation of BMW management rules while only $25 \%$ of the class IV workers had good knowledge regarding the same.

The fact that the biomedical waste should be treated before disposal was known by the CRRIs (68.7\%) more compared to the other groups. Knowledge regarding the hazard of improper BMW disposal and the availability of vaccine for Hepatitis B was good among 
CRRIs (87.5\%) while it was poor among lab technicians and class IV workers. CRRI s and Lab technicians were able to correctly identify the symbol of bio-hazard compared to the other groups. Knowledge, with respect to, concern for needle stick injury as well as universal precaution was good among almost all the groups of health professionals examined (Table 1).

The importance of biomedical waste segregation disposal and treatment was accepted among the various groups of health professionals. Majority of the laboratory technicians opined that the segregation treatment and disposal though important adds burden to their work. Varying percentages of health professionals understood that financial burden of the hospital is increased because of BMW management with higher percentage among lab technicians. All health care employees had the attitude that the BMW implementation is their responsibility. There was a positive response in attending training classes among all the groups of health care workers (Table 2).

Almost all the health care professionals (around 80\%) reported that needles should be discarded in puncture proof container. Lab technicians among others had good knowledge in disposal of blood bags and uro bags in yellow and red bags respectively. Most of the personnel were not able to report the disposal method of broken thermometers. Many followed correct disposal method for expired drugs, POP, metallic implants.

Most of the laboratory technicians had completed the course of Hepatitis B vaccination while only $40 \%$ of the heath care workers were vaccinated completed. The CRRIs though had minimal percentage for complete vaccination coverage majority had completed 2 doses and are yet to complete the vaccination schedule (Table 3 ).
The present study revealed that majority of the CRRI $s$ and staff nurses had good knowledge and practices in Biomedical waste management with least performance among the class IV workers as shown in other studies [6-9]. The knowledge and awareness about the Biomedical waste and its hazards and the diseases transmitted were high among the CRRI $s$ and staff nurses than laboratory technicians and class IV workers. This might be because of the strict adherence and participation to the training sessions by the interns and the staff nurses and surveillances of these activities conducted periodically in our hospital.

It was also noted that the concern regarding the needle stick injury was less comparatively among the paramedical staffs (lab technicians). Similar findings were reported in other studies also $[6,7,10,11]$. Lack of awareness among the health care personnel is a serious issue and predisposes them to infections like HIV, Hepatitis B, and Hepatitis C etc.

The lack of awareness among the class IV workers regarding the universal precautions is a matter of concern as they are involved in direct handling of the waste during collection, transport and storage in the common storage room.

The attitude of the paramedical staff who opined that the BMW management adds extra burden to their work is quite alarming. This is worrisome and such attitude must be changed and the significance of proper disposal and management of BMW should be stressed. It must not be addressed as a extra burden of work. The study also revealed that few of the health care professionals are still not aware of the disposal of the needles in puncture proof container and such ignorance will predispose to needle stick injuries. These findings were also reported in other studies [6, 10-13]. 
The disposal of broken thermometers was a confusion among most of them as the latest guidelines did not include the method of disposal of mercury.

From our present study it can be concluded that the knowledge and awareness is less among the health care workers and inadequate and poor among the class IV workers. Frequent training sessions followed by the surveillance of their activities by a team would help to reinforce the importance of proper biomedical waste management. The awareness about the need for vaccination against hepatitis B is present among all the groups but only a minority has completed all three doses of the vaccination schedule. Overall a positive attitude among the health care workers regarding the BMW management is needed and implementing which the transmission of diseases through the mismanagement of the waste could be greatly reduced.

\section{Limitations}

The study however cannot be generalised since it was performed at one centre and the target population did not include doctors. The number of participants in each group was not equal and so the comparison of percentages might be in appropriate.

\section{References}

1. Mathur V, Dwivedi S, Hassan MA, Misra RP. Knowledge, attitude and practices about Bio-medical waste management among health care personnel: a cross-sectional study. Indian Journal of Community Medicine. 2011; 36: 143-5.

2. Government of India, Ministry of Health and Family Welfare (MoHFW). National Guidelines on Hospital Waste Management Based upon the Bio-
Medical Waste (Management and Handling) Rules, 1998. New Delhi: MoHFW. 2002.

3. Patil AD, Sekhdar AV. Health- Care Waste Management in India, J Environ Manage. 2001; 63: 211-20.

4. Safe management of waste from health care activities. WHO, Geneva. 1999.

5. Central pollution control board. Environmental standard and guidelines for management of hospital waste. CPCB, Ministry of Environment and Forest, New Delhi. 1996.

6. Malini A, Eshwar B. Knowledge, Attitude and Practice of Biomedical waste management among health care personnel in a tertiary care hospital in Puducherry International Journal of Biomedical Research. 2015; 6(03): 1726.

7. Sharma A, Sharma V, Sharma S, Singh P. Awareness of Biomedical Waste Management Among Health Care Personnel in Jaipur, India. Oral Health and Dental Management. 2013; 12(1): 32-40.

8. Sharma S. Awareness about biomedical waste management among health care personnel of some important medical centres in Agra. International Journal of Environmental Science and Development. 2010; 1: 251-5.

9. Narang RS, Manchanda A, Singh S, Verma N, Padda S. Awareness of biomedical waste management among dental professionals and auxiliary staff in Amritsar, India. Oral Health and Dental Management. 2012; 11: 162-8.

10. Chudasama RK, Rangoonwala M, Sheth A, Misra SKC, Kadri AM, Patel UV. Biomedical Waste Management: A study of knowledge, attitude and practice among health care personnel at tertiary care hospital in Rajkot. J Res Med Den Sci. 2013; 1: 17-22. 
11. Sharma A, Sharma V, Sharma S, Singh P. Awareness of Biomedical Waste Management Among Health Care Personnel in Jaipur, India. OHDM. 2013; 12(1): 32-40.

12. Ismail IM, Kulkarni AG, Kamble SV, Borker SA, Rekha R, Amruth M. Knowledge, attitude and practice about bio-medical waste management among personnel of a tertiary health care institute in Dakshina Kannada, Karnataka. Al Ameen J Med Sci. 2013; 6(4): 376-80.

13. Palwankar PV, Singh A. Safety and measures for auxiliary staff associated with hospital waste disposal. Indian Journal of Dental Sciences. 2012; 4: 104-6.

\section{How to cite this article:}

Deepika, K. 2019. Knowledge Attitude and Practice of Biomedical Waste Management among Health Care Workers in a Tertiary Care Hospital, Coimbatore, India. Int.J.Curr.Microbiol.App.Sci. 8(07): 1893-1897. doi: https://doi.org/10.20546/ijcmas.2019.807.225 